\title{
Laser-Induced Incandescence Calibration via Gravimetric Sampling
}

R.L. Vander Wal

NYMA, Inc.

Brook Park, Ohio

and

Z. Zhou and M.Y. Choi

University of Illinois at Chicago

Chicago, Illinois

June 1996

Prepared for

Lewis Research Center

Under Contract NAS3-27186

National Aeronautics and

Space Administration 


\title{
Laser-Induced Incandescence Calibration via Gravimetric Sampling
}

\author{
R.L. Vander Wal \\ NYMA, Inc. \\ 2001 Aerospace Pkwy. \\ Brook Park, OH 44142 \\ @NASA Lewis Research Center \\ Z. Zhou and M.Y. Choi \\ Department of Mechanical Engineering \\ University of Illinois at Chicago \\ Chicago, IL 60607
}

\section{Introduction}

Soot volume fraction $\left(f_{v}\right)$ measurements are central to studies of soot growth and radiant transport processes within flames. ${ }^{1,2}$ In the post-flame region, soot yield and specific extinction coefficient per unit mass of fuel consumed in addition to $f_{v}$ are key quantities of interest. ${ }^{3,4}$ Light extinction is widely used for measuring these quantities but possesses limitations. ${ }^{5}$ Interpretation of extinction measurements to determine $f_{v}$ or soot yields rely on assumptions and uncertainties regarding soot properties. Varying experimental conditions can affect the contributions to the extinction measurement of absorption by PAH's and scattering, hence these contributions are often neglected.

Laser-induced incandescence (LII) has recently emerged as an alternative technique for determining $f_{v}{ }^{6-18}$ In the LII technique, a pulsed high energy laser is used to heat soot to incandescence temperatures. With suitable spectral filtering and temporal collection, the emission from the laser-heated soot (which is blue-shifted and dramatically increased) may be distinguished relative to the non-laser heated soot and flame gases. Laser-induced incandescence (LII) offers significant advantages compared to extinction measurements in determining $f_{v}$. LII has been shown to possess temporal resolution of $10 \mathrm{~ns}$ for both point and planar measurements. ${ }^{9-18} \mathrm{LI}$ also is immune to absorption contributions by polycyclic aromatic hydrocarbons (PAH's). Furthermore LII possesses geometric versatility as it is not a line-of-sight technique. ${ }^{9}$ Recent applications have included gas-jet diffusion flames, ${ }^{9,11,12,16}$ both fiber-supported and freely falling burning droplets, ${ }^{10,17,18}$ premixed flames ${ }^{9}$ and measurements within diesel engines. ${ }^{14,15}$

Previous calibrations of the LII signal have compared LII signals from point measurements or limited spatial regions within diffusion flames where $f_{v}$ was determined by prior extinction measurements. ${ }^{10,11,12,15}$ Such calibration by comparison introduces all of the uncertainties regarding the soot refractive index and scattering behavior to the LII-determined $f_{v}$. An ideal calibration of the LII signal should be independent of the soot refractive index and allow calibration over the entire imaged region for both one-dimensional and two-dimensional measurements. GS is used here to achieve calibration of LII.

The technique of gravimetric sampling allows determination of $f_{v}$ independent of soot optical properties. ${ }^{5}$ Gravimetric sampling (hereafter referred to as GS) consists of isokinetically sampling the soot at a known flow rate and measuring the mass of soot collected. Using the density of soot provided by helium pycnometry measurements, accurate values of the $f_{v}$ can be determined. Notably, this $f_{v}$ does not depend upon optical properties of soot and is insensitive to scattering effects and absorption by PAH molecules. GS has recently been used in the post-flame region for determination of the $f_{v^{*}}{ }^{5}$

\section{Experimental Description}

Various beam imaging and/or sheet forming optics delivered light at $1064 \mathrm{~nm}$ from a pulsed Nd:YAG laser for use either as a beam of $3 \mathrm{~mm}$ radius or as a laser sheet. Imaging measurements were performed with a gated intensified array camera equipped with a UV f4.5 lens and $40 \mathrm{~mm}$ extension tube. Point measurements were performed using an ultraviolet $250 \mathrm{~mm}$ focal length lens to collect and focus the LII signal into a 1 meter long quartz optical fiber which directed the LII signal to a $1 / 4$ meter monochromator. An aperture preceding the lens restricted the signal collection region to $1 \mathrm{~cm}$ along the laser beam at the center of the gravimetric chimney. Signals from the PMT were processed by a boxcar integrator whereas the images were captured digitally using a frame-grabber with 16 MByte of on-board memory. Both 'point' and planar measurements were made with detector gates of $250 \mathrm{~ns}$ to minimize possible morphology bias in collection of the LII signal. Additionally, the imaging measurements were performed with broadband spectral collection of the LII signal to maximize the signal and again minimize any potential effects of morphology dependent heating and/or cooling rates. Digital delay generators controlled the firing of the laser, detector gates and data acquisition. Neutral density filters were 


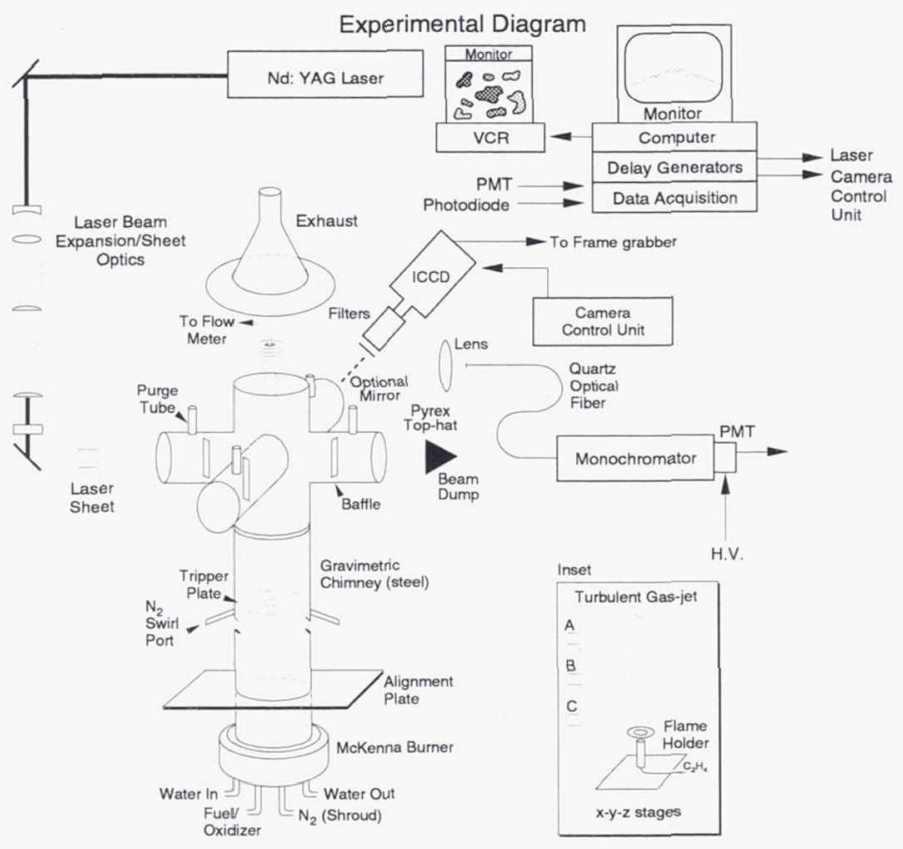

Figure 1.-Experimental diagram.

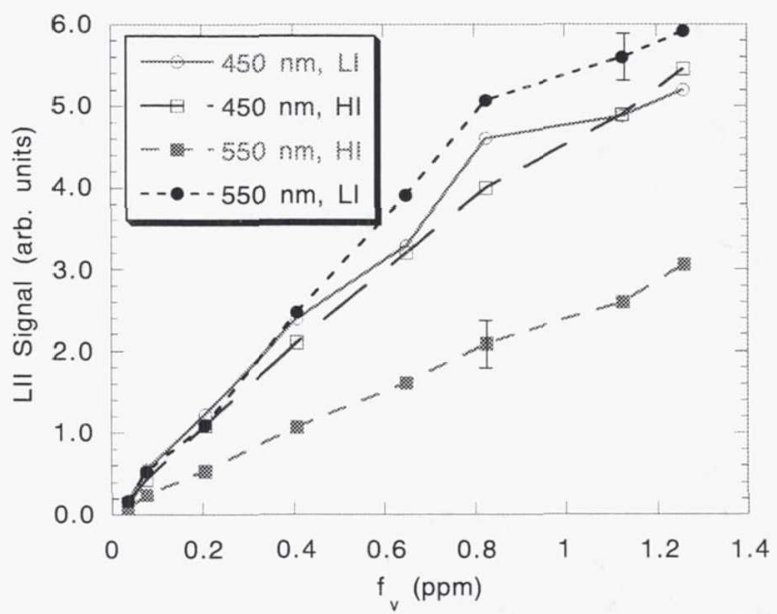

Figure 2.-Dependence of LII signal upon $f_{v}$ at laser intensites of $2.9 \times 10^{7}$ and $5.7 \times 10^{7} \mathrm{~W} / \mathrm{cm}^{2}$ with detection at wavelengths of 450 and $550 \mathrm{~nm}$ using a $1 \mathrm{~nm}$ spectral bandpass.

used for both sets of measurements to maintain signal levels within linear dynamic ranges of the detectors, the range being determined prior to experiments.

Figure 1 illustrates the experimental layout. The GS tube and sampling technique have been previously described. ${ }^{5} \mathrm{~A}$ rich mixture of acetylene/air with $\mathrm{C} / \mathrm{O}$ ratios from 1.53 to 2.49 were used to produce the soot dispersion with mixing provided by swirling $\mathrm{N} 2$ flow through the two ports attached to the side of the steel chimney. A stainless steel tripper plate is also installed $17 \mathrm{~cm}$ from the base of the chimney to further promote mixing. Mass flow-controllers were used to meter all gas flows to the burner and GS chimney. A pyrex 'top-hat' equipped with baffles in the side arms provided optical access at the top of the GS chimney. Nitrogen was injected at approximately $20 \mathrm{ml} / \mathrm{min}$ outside of the baffle in each sidearm to prevent soot collection in the sidearms. For calibration measurements, the laser sheet intensity and imaging conditions were kept constant while a $0.78 \mathrm{~mm}$ outer diameter nozzle replaced the GS chimney for the turbulent ethylene diffusion flame.

\section{"Point" Characterization}

A disadvantage of single-point calibrations (using one value of $f_{v}$ and corresponding LII signal) performed to-date is that one value of $f_{v}$ in a previously determined system is used as a reference for other applications. This value of $f_{v}$ or the corresponding LII signal may not fall within the dynamic range of the detector when adjusted for the application; hence either the calibration must be made with different detector gains or signals from the application must be attenuated to achieve comparison. Using the GS technique, the value of $f_{v}$ to serve as calibration may be adjusted either by varying the $\mathrm{N} 2$ swirl addition or $\mathrm{C} / \mathrm{O}$ ratio of the flame. Such variation may allow multipoint calibration, enabling interpolation of $f_{v}$ values in applications and possible correction for detector nonlinearities. Preliminary measurements have shown that $f_{v}$ varies much more with $\mathrm{C} / \mathrm{O}$ ratio than with changes in $\mathrm{N} 2$ swirl addition.

For C/O ratios of 1.53 to 2.49 , we found $f_{v}$, determined via gravimetric sampling, varied by over an order of magnitude, from 0.035 to $1.5 \mathrm{ppm}$. Figure 2 compares the LII signal obtained at two different intensities of $2.9 \times 10^{7} \mathrm{~W} / \mathrm{cm}^{2}$ (referred to as low intensity, LI, in the Fig.) and $5.7 \times 10^{7} \mathrm{~W} / \mathrm{cm}^{2}$ (referred to as $\mathrm{HI}$ in the Fig.) at each of two detected wavelengths of 450 and $550 \mathrm{~nm}$ with bandwidths of $1 \mathrm{~nm}$ using the beam geometry. The curves are uncorrected for the spectral response of the detection system but the relative magnitudes of the signals are accurate. The error bars $(1 \sigma)$ reflect the reproducibility of themeasurements. Excellent linearity is observed at both detection wavelengths with each $\sigma$ laser intensities.

\section{Imaging Characterization}

To serve as a calibration device for imaging applications, both temporal and spatial uniformities of $f_{v}$ over the entire imaged region are critical. Single laser-shot LII images as shown in Fig. 3b-3d clearly reveal dramatic variations in the spatial distribution and magnitude of $f_{v}$. These images were obtained using a C/O ratio of 1.99 and a $\mathrm{N} 2$ swirl addition of 

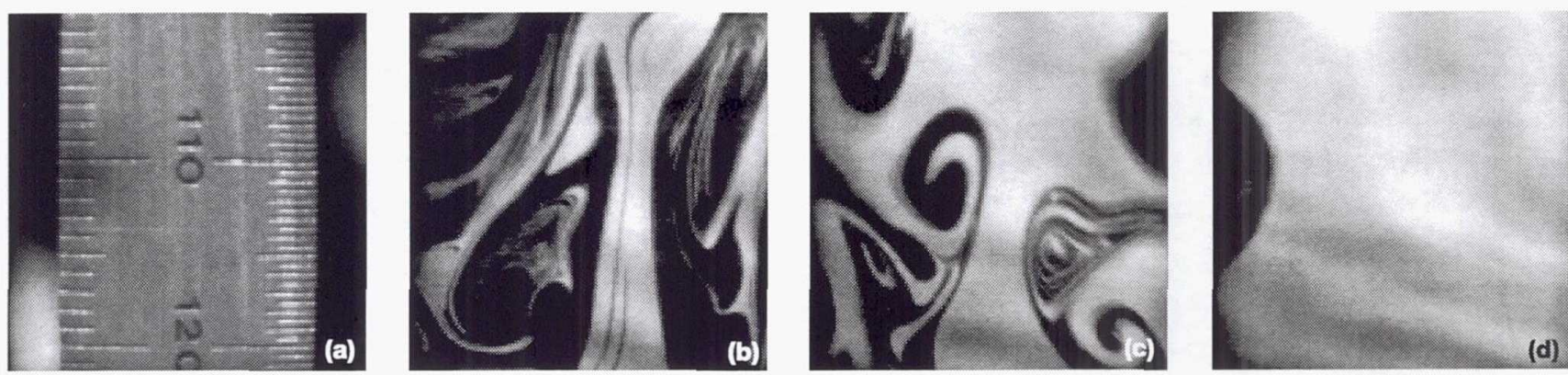

Figure 3.-Spatially resolved single laser-shot LII images obtained within the GS chimney.

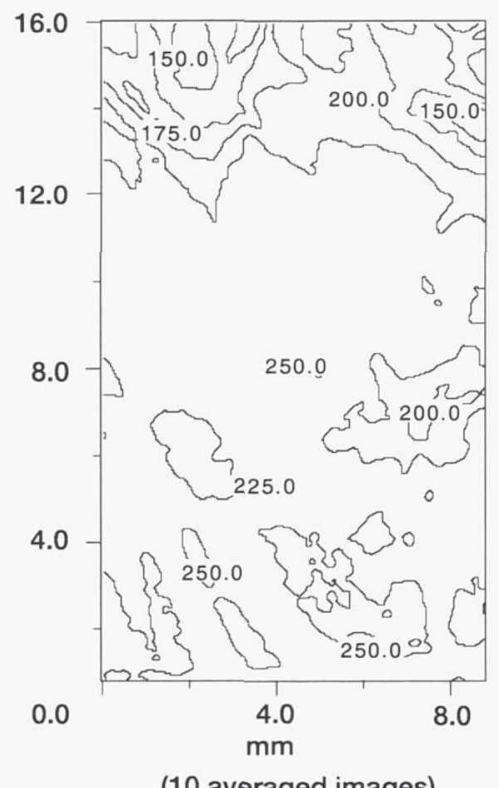

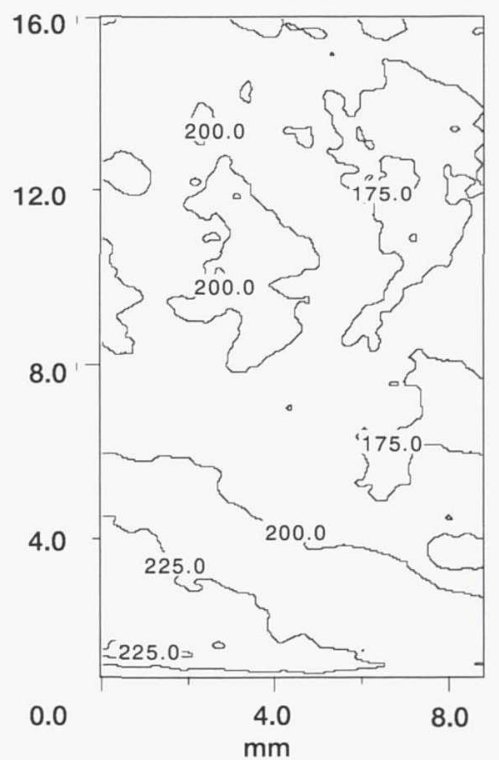

(40 averaged images)

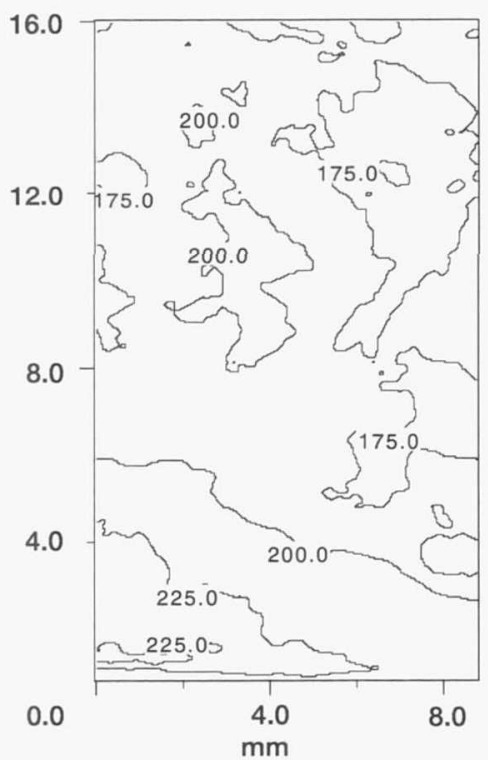

( 80 averaged images)

Figure 4.-Contour plots of representing the temporal average of 10, 40 and 80 temporally uncorrelated LII images.

20 slpm. An image of a metric ruler, Fig. 3a, (millimeter scale) placed in the LII image plane prior to measurements gives the spatial scale of the LII images (Fig. 3b-3d). While some LII images reveal a rather uniform $f_{v}$, (Fig. 3d) others clearly do not (Fig. 3b-3c). Since the GS technique determines an absolute value of $f_{v}$ by sampling the soot containing gases for a period of several minutes, a similar temporal averaging approach can be applied to spatially resolved LII calibration images. Figure 4 shows three contour plots, each representing an image obtained by averaging different numbers of temporally uncorrelated single laser-shot LII images for the 'worst case' scenario of using no N2 swirl addition to promote mixing. The number in each panel indicates the number of images averaged to produce the image. The contours represent intensity levels between 150 and 250 in steps of 25 . Rapid convergence to a fixed contour pattern is readily shown in this figure. This rapid convergence of the LII images validates use of path integrated light extinction measurements for calculation of $\mathrm{Ke}$ (dimensionless extinction constant) values by comparison with the GS sampling technique ${ }^{5}$ and supports the GS technique for obtaining a representative measure of $f_{v}$ since the averaged LII images reveal small radial variation.

The main purpose of the $\mathrm{N} 2$ swirl is to provide dilution, homogenize the soot and reduce the temperature of the soot dispersion in the post-flame gases. For purposes of imaging calibrations, different N2 flow rates mainly affect the degree of spatial uniformity of $f_{v}$ and hence the temporal averaging necessary to converge to a uniform calibration image. Larger N2 swirl additions led to generally more uniform images and consequently less temporal averaging was necessary to converge to a final pattern as judged from horizontal and vertical profile plots through the temporally averaged images obtained at different N2 swirls. With sufficient temporal averaging of individual LII images, each N2 addition rate with its rather different turbulence patterns led to similar LII intensity patterns. As illustration of the general uniformity of the central region of the soot field within the gravimetric chimney, Fig. 5 show a surface plot of an average of 80 single lasershot LII images. A N2 swirl addition of 20 slpm was used with a C/O ratio of 1.99 for the flame. General radially uniform 


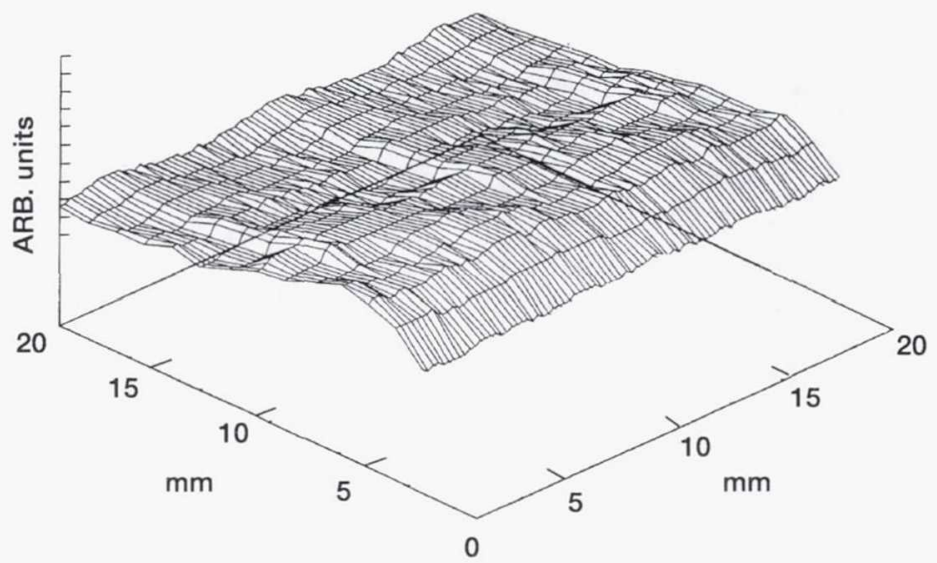

Figure 5.- Surface plot of the LII intensity of the average of 80 single laser-shot temporally uncorrelated LII images obtained at a N2 swirl addition of 20 slpm and $\mathrm{C} / \mathrm{O}$ ratio of 1.99

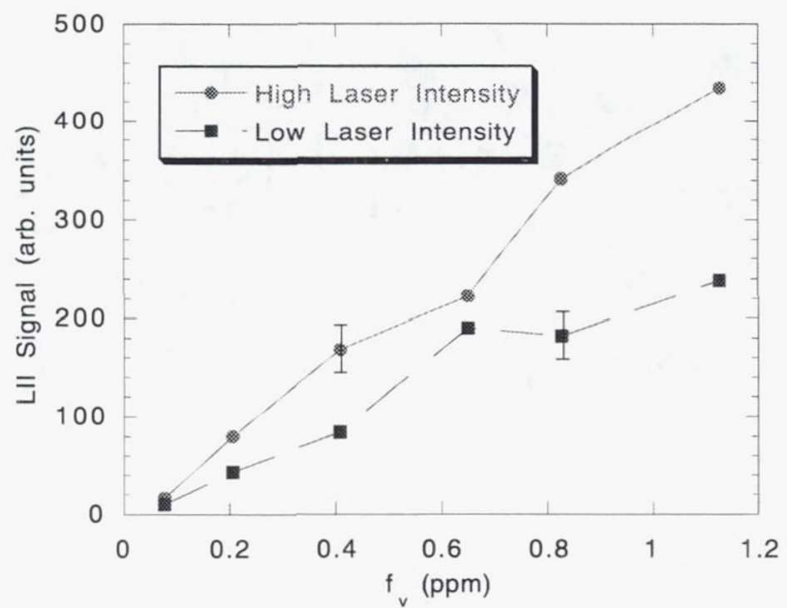

Figure 6.-Dependence of spatially averaged LII intensity detected by the camera with $f_{v}$ using two different laser intensities of $2.5 \times 10^{7}$ and $5.0 \times 10^{7} \mathrm{~W} / \mathrm{cm}^{2}$.

intensity is shown in this plot. Nonuniformities in the temporally averaged LII image, we believe, reflect intensity variations in the laser sheet, transmission variation in the detection optics and gain variation within the camera rather than nonuniformities in $f_{v}$ over the central region within the GS chimney. Such an image may then be used to correct for energy variation in the laser sheet and nonuniformities in the optical detection system. Such correction has only been performed to-date for visible and ultraviolet laser sheets for linear signal processes based on either fluorescence or scattering. Secondly, the similar and uniform profiles (as typified by Fig. 5) were observed at different N2 swirl additions suggesting that the fluctuations observed in $f_{v}$ in single laser-shot LII images are indeed random and temporally uncorrelated.

\section{Application/Calibration}

To assign absolute $f_{v}$,'s to an LII image, a calibration factor is needed relating pixel intensity to $f_{v}$. First, spatially averaged image intensities are calculated from a series of LII images (temporally uncorrelated) which were obtained at a laser intensity of $5.0 \times 10^{7} \mathrm{~W} / \mathrm{cm}^{2}$. The average of these values is then equated to the value of $f_{v}$ determined by GS. Single laser-shot LII images illustrate a nonuniform and chaotic spatial and temporal variation in $f_{v}$. A temporal average of individual LII images, however, rapidly converges towards a final uniform pattern in a time short compared with the GS sampling time ( 30 individual LII images obtained at $10 \mathrm{~Hz}$ compared to minutes of GS time) thus validating the assignment of $f_{v}$ to the average pixel intensity obtained by spatially and temporally averaging several LII images. Averaging greater than 30 images in this manner assured invariance of the calculated average pixel intensity upon additional averaging. This calibration procedure was then performed for three different $\mathrm{C} / \mathrm{O}$ ratios of $1.75,1.99$, and 2.23 with a N2 swirl addition of 20 slpm yielding gravimetrically determined $f_{v}$ 's of $0.21,0.65$ and 1.13 ppm respectively. Each measurement yielded an identical calibration factor within experimental error. The average of these three measurements was then used to assign soot ppm levels to pixel intensity values.

Independent measurements testing the linearity of the camera detection system with $f_{v}$ were performed by varying the $\mathrm{C} / \mathrm{O}$ ratio of the flame from 1.64 to 1.13 with resulting $f_{v}$ values ranging from 0.078 to 1.13 ppm determined via GS. For each C/O ratio, the temporally and spatially averaged image intensity of a series of LII images was calculated as described above and is plotted in Fig. 6 versus the GS determined $f_{v}$ produced by that C/O ratio. A N2 swirl addition of 20 slpm was used for all measurements. Different neutral density filters were used to maintain the LII signal within the dynamic range of the camera. Linearity between the LII signal as detected by the camera and $f_{v}$ using two different laser intensities of 2.5 $x 10^{7} \mathrm{~W} / \mathrm{cm}^{2}$ and $5.0 \times 10^{7} \mathrm{~W} / \mathrm{cm}^{2}$ is demonstrated.

Figure 7 shows a series of single laser shot images of a turbulent ethylene gas-jet flame $(\operatorname{Re}=5000)$, at three different heights as indicated, above the nozzle. The images were selected as representative of a series of LII images taken at the different heights. A steel disc with an $8 \mathrm{~mm}$ diameter hole placed $9 \mathrm{~mm}$ above the nozzle anchored the gas-jet. The spatial scale is illustrated by the ruler at the bottom of Fig. 7c \& 7f with markings in millimeters. Absolute $f_{v}$ 's from the turbulent gas-jet flame were determined by the calibration procedure described earlier. The contour plots in Fig $7 \mathrm{~d}-\mathrm{f}$ represent $f_{v}$ in ppm. Only the high temporal and spatial capabilities of LII are capable of revealing the instantaneous detailed spatial and temporal variation of $f_{v}$. 

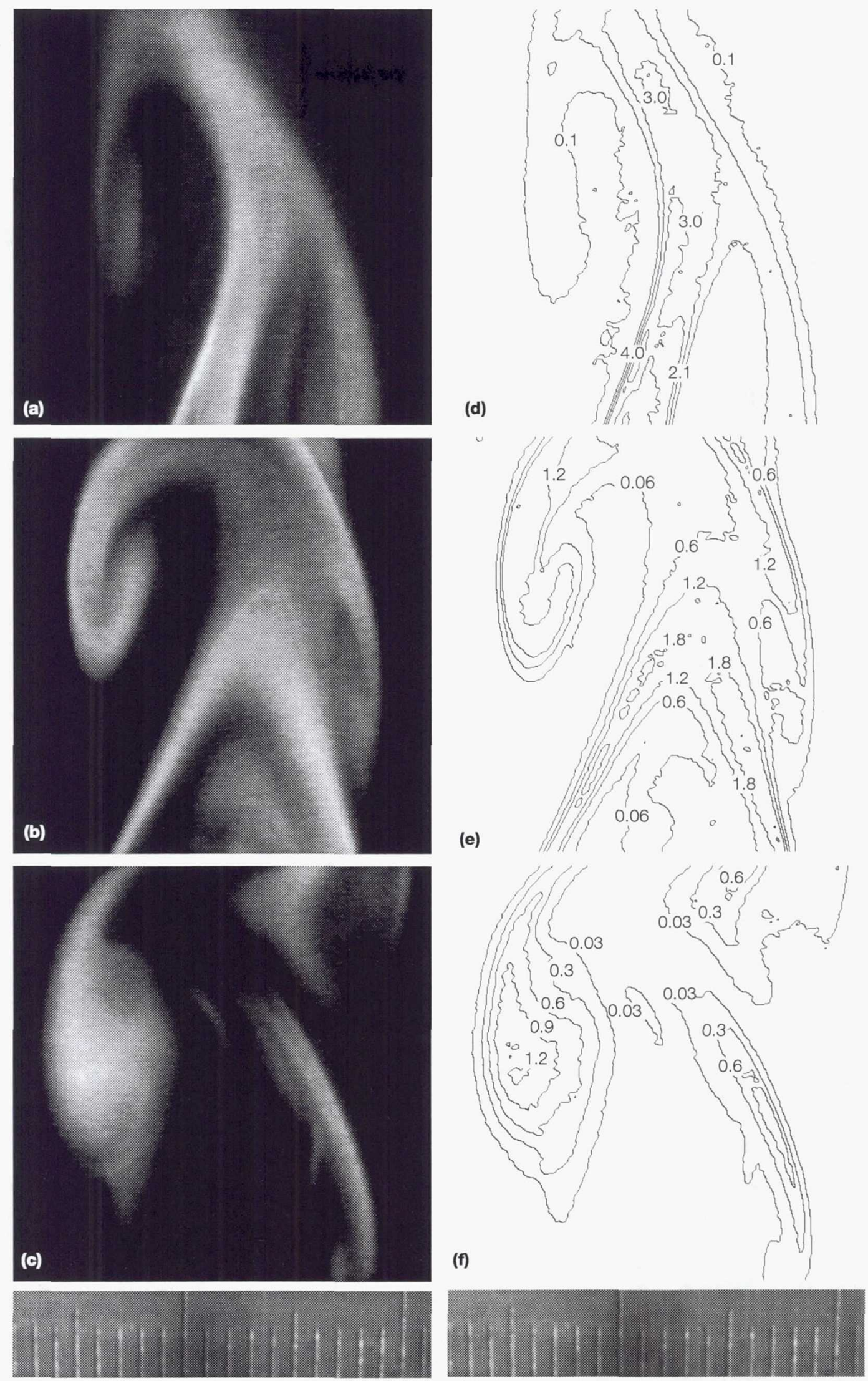

Figure 7.- LII images (a-c) of a $\mathrm{Re}=5000$ turbulent ethylene gas-jet diffusion flame. The bottom of each image corresponds to positions of $9.5,14.5$ and $19.5 \mathrm{~cm}$ above the nozzle. The ruler at the bottom of panels $\mathrm{c}$ and $\mathrm{f}$ is in millimeters. The contour plots in panels d-f represent $f_{v}$ of the corresponding LII image in ppm, determined as described in the text. 


\section{Conclusions}

With appropriate spectral, spatial and temporal characterization of the soot field within the gravimetric chimney, the technique of gravimetric sampling offers a calibration method for point, one- and two-dimensional LII images. Such characterization of the temporal and spatial fluctuations in the soot field within the gravimetric chimney can only be provided by LII. Variation of $f_{v}$ of the soot field may be achieved by varying the $\mathrm{C} / \mathrm{O}$ ratio of the flame. Such variation can allow for interpolation of LII signals from applications, allow calibrations for widely varying levels of $f_{v}$ and offers empirical calibration for nonlinear detectors. The most significant advantage of the gravimetric sampling technique for calibration of the LII signal is in obtaining values for $f_{v}$ independent of uncertainties in the refractive indices of soot. Accurate absolute calibration of the LII signal in conjunction with the temporal and spatial resolution of LII provides a tool for determination of $f_{v}$ in systems previously amenable only to temporally averaged quantities such as illustrated by the turbulent gas-jet flame.

\section{Acknowledgements}

RVW gratefully acknowledges aid from Dr. Daniel L. Dietrich of NASA-Lewis in processing images, and support under NASA contract NAS-327186. ZZ and MYC would like to acknowledge support from NIST under grant \#60NANB4D1650 with Mr. N. Bryner serving as the Scientific Officer and the helpful advice of Dr. George Mulholland of NIST.

\section{References}

1. Santoro, R.J., Yeh, T.T., Horvath, J.J. and Semerjian, H.G., Comb. Sci. Tech., 53:89 (1987).

2. Harris, S.M. and Weiner, A.M., Comb. Sci. Tech., 31:156 (1983).

3. Newman, J.S. and Steciak, J., Comb. Flame, 67:55 (1987).

4. Mulholland, G.W., Henzel, V. and Babrauskas, V., Proceedings of the Second International Symposium on Fire Safety Science (T. Wakamatsu, Y., Hasemi, A. Sekizawa, P.G. Seeger, P.J. Pagni and C.E. Grant, Eds). Hemisphere, N.Y., p. 347 (1989).

5. Choi, M.Y., Mulholland, G.W., Hamins, A. and Kashiwagi, T., "Comparisons of the Soot Volume Fraction Using Gravimetric and Light Extinction Techniques", Comb. Flame, to appear (1995).

6. Eckbreth, A.C., J. Appl. Phys., 48:4437 (1977).

7. Melton, L.A., Appl. Opt., 23:2201 (1984).

8. Hofeldt, D.L., SAE Technical Paper 930079, International Congress and Exposition, S.F. CA, (1993).

9. Vander Wal, R.L. and Weiland, K.J., J. Appl. Phys B., in press. (1994).

10. Vander Wal, R.L. and Dietrich, D. J., Appl. Opt., in press. (1994).

11. Quay, B., Lee, T.W., Ni, T. and Santoro, R.J., Comb. Flame, 97:384 (1994).

12. Shaddix, C.R., Harrington, J.E. and Smyth, K.C., Twenty-Fifth Symposium (Int'l) on Combustion, The Combustion Institute, in press. (1994).

13. Vander Wal, R.L., Choi, M.Y. and Lee, K.O., "The Effects of Rapid Heating of Soot: Implications When Using LaserInduced-Incandescense for Soot Diagnotistics", Comb.Flame, submitted (1994).

14. Dec, J. E., zur Loye, A. O., Siebers, D. L.: SAE Technical Paper 910224, International Congress and Exposition, Detroit, Michigan, Feb.-March, (1991).

15. Pinson, J. A., Mitchell, D. L., Santoro, R. J. and Litzinger, T. A., SAE Technical Paper 932650, Fuels and Lubricants Meeting, Philadelphia Pennsylvania, Sept. 18-21, (1993).

16. Cignoli, F., Benecchi, S. and Zizak, G., Appl. Opt. 33:5778, (1994).

17. Gupta, S.B., Ni. T. and Santoro, R.J., "Spatial and Time Resolved Soot Volume Fraction Measurements in Methanol/ Toluene Droplet Flames", Presented at the Technical Meeting of the Eastern States Section of the Combustion Institute, Clearwater Beach, FL., (1994).

18. Vander Wal, R.L., Dietrich, D.L. and Choi, M.Y., "Relative Soot Volume Fraction in Droplet Combustion via LaserInduced-Incandescense", Presented at the Technical Meeting of the Eastern States Section of the Combustion Institute, Clearwater Beach, FL., (1994). 
Public reporting burden for this collection of information is estimated to average 1 hour per response, including the time for reviewing instructions, searching existing data sources, gathering and maintaining the data needed, and completing and reviewing the collection of information. Send comments regarding this burden estimate or any other aspect of this collection of information, including suggestions for reducing this burden, to Washington Headquarters Services, Directorate for Information Operations and Reports, $1215 \mathrm{~J}$,
Davis Highway, Suite 1204, Arlington, VA 22202-4302, and to the Office of Management and Budget, Paperwork Reduction Project (0704-0188), Washington, DC 20503.

\begin{tabular}{|l|c|c|}
\hline 1. AGENCY USE ONLY (Leave blank) & $\begin{array}{c}\text { 2. REPORT DATE } \\
\text { June } 1996\end{array}$ & $\begin{array}{c}\text { 3. REPORT TYPE AND DATES COVERED } \\
\text { Final Contractor Report }\end{array}$
\end{tabular}

4. TITLE AND SUBTITLE 5. FUNDING NUMBERS

Laser-Induced Incandescence Calibration via Gravimetric Sampling

6. AUTHOR(S)

WU-656-61-23

R.L. Vander Wal, Z. Zhou, and M.Y. Choi

C-NAS3-27186

7. PERFORMING ORGANIZATION NAME(S) AND ADDRESS(ES)

8. PERFORMING ORGANIZATION REPORT NUMBER

NYMA, Inc.

2001 Aerospace Parkway

E-9551-1

Brook Park, Ohio 44142

9. SPONSORING/MONITORING AGENCY NAME(S) AND ADDRESS(ES)

10. SPONSORING/MONITORING AGENCY REPORT NUMBER

National Aeronautics and Space Administration

Lewis Research Center

NASA CR-198495

Cleveland, Ohio 44135-3191

11. SUPPLEMENTARY NOTES

Prepared for the Central States Section Meeting sponsored by The Combustion Institute, San Antonio, Texas, April 20-23, 1995. R.L. Vander Wal, NYMA, Inc., 2001 Aerospace Parkway, Brook Park, Ohio 44142; Z. Zhou and M.Y. Choi, Department of Mechanical Engineering, University of Illinois at Chicago, Chicago, Illinois 60607 (funded by NIST Grant 60NANB4D1650). Project Manager, Howard D. Ross, Space Experiments Division, NASA Lewis Research Center, organization code 6711, (216) 433-2562.

12a. DISTRIBUTION/AVAILABILITY STATEMENT 12b. DISTRIBUTION CODE

Unclassified - Unlimited

Subject Category 25

This publication is available from the NASA Center for AeroSpace Information, (301) 621-0390.

13. ABSTRACT (Maximum 200 words)

Absolute calibration of laser-induced incandescence (LII) is demonstrated via comparison of LII signal intensities with gravimetrically determined soot volume fractions. This calibration technique does not rely upon calculated or measured optical characteristics of soot. The variation of the LII signal with gravimetrically measured soot volume fractions ranging from 0.078 to $1.1 \mathrm{ppm}$ established the linearly of the calibration. With the high spatial and temporal resolution capabilities of laser-induced incandescence (LII), the spatial and temporal fluctuations of the soot field within a gravimetric chimney were characterized. Radial uniformity of the soot volume fraction, $\mathrm{f}_{\mathrm{v}}$, was demonstrated with sufficient averaging of the single laser-shot LII images of the soot field thus confirming the validity of the calibration method for imaging applications. As illustration, instantaneous soot volume fractions within a $\mathrm{Re}=5000$ ethylene/air diffusion flame measured via planar LII were established quantitatively with this calibration.

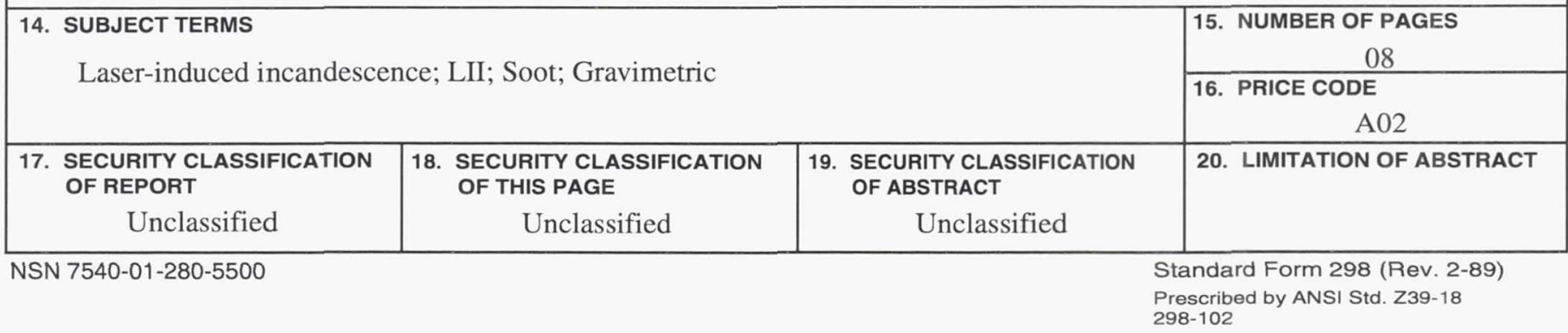




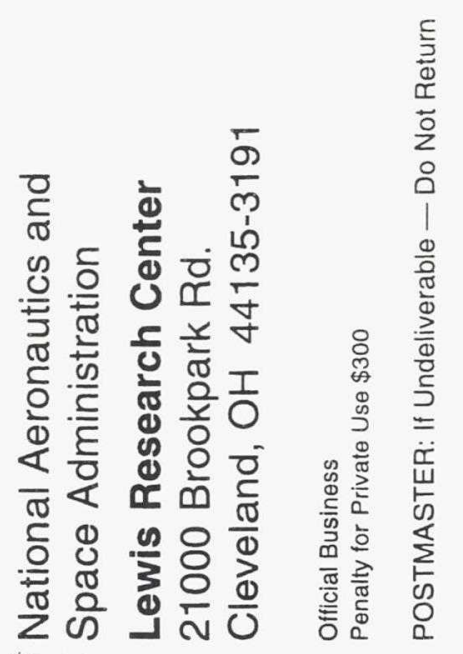

